\title{
Sound: Conceivably the creative language of God, holding all of creation in concert
}

\begin{tabular}{|c|}
\hline $\begin{array}{l}\text { Author: } \\
\text { Mark Pretorius }\end{array}$ \\
\hline $\begin{array}{l}\text { Affiliations: } \\
{ }^{1} \text { Research Associate, } \\
\text { Department of Dogmatics } \\
\text { and Christian Ethics, } \\
\text { University of Pretoria, } \\
\text { South Africa }\end{array}$ \\
\hline $\begin{array}{l}{ }^{2} \text { South African Theological } \\
\text { Seminary, Rivonia, } \\
\text { South Africa }\end{array}$ \\
\hline $\begin{array}{l}\text { Correspondence to: } \\
\text { Mark Pretorius }\end{array}$ \\
\hline $\begin{array}{l}\text { Email: } \\
\text { Mark@sats.edu.za }\end{array}$ \\
\hline $\begin{array}{l}\text { Postal address: } \\
\text { PO Box 258, Rivonia 2128, } \\
\text { South Africa }\end{array}$ \\
\hline $\begin{array}{l}\text { Dates: } \\
\text { Received: } 23 \text { Nov. } 2010 \\
\text { Accepted: } 31 \text { May } 2011 \\
\text { Published: } 03 \text { Nov. } 2011\end{array}$ \\
\hline $\begin{array}{l}\text { How to cite this article: } \\
\text { Pretorius, M., 2011, 'Sound: } \\
\text { Conceivably the creative } \\
\text { language of God, holding } \\
\text { all of creation in concert', } \\
\text { Verbum et Ecclesia } 32(1) \text {, Art. } \\
\# 485,7 \text { pages. http://dx.doi. } \\
\text { org/10.4102/ve.v32i1.485 }\end{array}$ \\
\hline $\begin{array}{l}\text { Note: } \\
\text { Dr Mark Pretorius is a } \\
\text { research associate of } \\
\text { Prof. Johan Buitendag } \\
\text { in the research area of } \\
\text { understanding reality in the } \\
\text { Department of Dogmatics, } \\
\text { University of Pretoria. He is } \\
\text { also on the staff of the South } \\
\text { African Theological Seminary. }\end{array}$ \\
\hline
\end{tabular}

(C) 2011. The Authors. Licensee: AOSIS OpenJournals. This work is licensed under the Creative Commons Attribution License.
This paper revolved around the idea that sound within light is the primary medium God used to bring all of creation into existence (creatio). The theory is that the harmonic tones embedded within the initial spoken light of Genesis 1:3 are still reverberating within creation today (concursus) and can be used for the benefit of all (providentia). This simply means that nature is providentially geared to move in a specific direction, according to God's overall plan for everyone's benefit.

\section{Introduction}

There is unquestionably an emergent realism and humility with reference to the discourse of the two disciplines of science and religion. In numerous respected circles, these two disciplines are envisaged as complementary approaches in seeking to comprehend reality. This is revealed by each one's mental models of reality that are inevitably incomplete in their respective disciplines. Based on this presupposition, there is, in my view, sufficient justification to bring science and religion into discussion to further the general understanding of what reality is. The dual importance of the elements of sound and light is probably a most promising aspect of this transversal space between science and religion and is certainly worth pursuing. It should be noted that although a detailed argument of all the disciplinary approaches to God which employ sound and light as mediums of creation is not probable in one paper, I have endeavoured to allude succinctly to them, to strengthen the underlying principle of the paper itself.

It is my belief that to come to terms with the aspect of sound which is embedded within the initial light of creation, an accurate understanding of reality necessitates that this element be investigated as well, primarily from a creationist perspective. Whether specifically from a physical and evolutionary idea or from a religious one, a foundation for investigation must be identified. Thus I am confident that, by engaging the different opinions proposed by physics, philosophy and religion, one would be in a healthier position to reason and put forward a theistic ${ }^{1}$ persuasion concerning reality, which details exclusively the argument that sound was, and is, one of the mediums employed by God in creating, providing and keeping his creation.

Besides this, the concept of 'sacred sounds' can be uncovered in numerous mystic writings. According to Elson (2004):

The secrets of sacred sound has [sic] been hidden for centuries. They are buried deep within the Kabbalah [a school of thought concerned with the mystical aspect of Judaism], as well as in such mystical writings as Gikatila's Sha'ar haNekud.

(Elson 2004:33)

Furthermore, Elson (2004:113) asserts that the Sefer Yetzirah (the title of the earliest extant book on Jewish esotericism), teaches that sound was God's primary creative influence. Hence the following question needs to be asked: can sound be deemed a biblically feasible process through which God realised creation and can it be scientifically verified?

\section{The science of sound}

The overarching premise to be argued throughout this paper centres on the question of whether sound frequencies and vibrations have the potential to create and whether it is theologically sagacious to assert that God was the ultimate source of this sound, or more specifically sacred sound, embedded within the initial light, thereby bringing into existence reality as presently observed. This particular field of study is referred to as Cymatic Theology (Pretorius 2008:1-4).

In this frame of mind, one needs to commence with the mathematical theory of differential equations first developed within the natural sciences. In this theory, differential equations are

1.See my PhD thesis for this, entitled "Understanding Reality: Exploring the Interaction between theology and science, with special reference to a theistic presupposition to certain worldviews', published by the University of Pretoria in 2007. 
used to model the behaviour of complex systems. Einstein was almost certainly the first person to present this theory to a wider scientific audience when he presented a paper on unified field equations to the Scientific American journal. In it, Einstein (1950:13-17) declares that everything in our reality is made up of waveforms that are harmonically unified. Sound, light and colour, for example, are ultimately equivalent to energy. As an illustration, consider the propagation of light and sound in the atmosphere and of waves on the surface of a pond. Each action can be described by the same second order partial differential equation. This wave equation permits us to ruminate on light and sound as forms of waves, much like the familiar action of waves in water.

Einstein went on to prove in his theory that all matter is energy (developing the now famous equation of $E=m \mathrm{c}^{2}$ ); hence, nothing in the universe is still but rather is vibrating or oscillating at some level. These vibrations generate sound waves (waveforms). Consequently, a wave (electromagnetic radiation in this case) is seen as a disturbance that propagates (travels) through the vacuum of space and time, commonly by the transference of energy (Sklar 1977:195). As a result, the hypothesis presented ostensibly maintains that all naturally occurring structures and shapes - from the subatomic electron to the individual atomic elements, and from microscopic forms to planets, stars and galaxies, were formed and sustained by sound (vibrating energy or electromagnetic radiation) conveyed by light. Today, this is known as the 'super string theory'.

\section{According to Porter (2008):}

In super string theory, the subatomic particles we see in nature are nothing more than different resonances of the vibrating superstrings, in the same way that different musical notes emanate from the different modes of vibration of a violin string. The forces between charged particles are the harmonies of the strings; the Universe is a symphony of vibrating strings. And when strings move in 10-dimensional space-time, they warp the space-time surrounding them in precisely the way predicted by general relativity. So strings simply and elegantly unify the quantum theory of particles and general relativity.

(Porter 2008:40)

Vis-à-vis, Donlan (2008:198) advances the notion that Von Neumann's concept of a conscious universe originating within subatomic vibrations is correct. For both Donlan and Porter, the universe is, in the purest sense, 'a vibratory thought process', lining up with Einstein's theory of unified field equations. With this in mind, one can also envisage the effect that sound (vibrating tones) has in affording us a particular view of the universe, which helps to unravel some of its mysteries. This universal principle employed today is known as 'redshift'.

\section{Redshift and the Doppler Effect}

For many decades now, scientists have been using a combination of sound and light as a method of measuring the distance of celestial bodies and the velocity at which the universe is expanding, an effect called a 'redshift'. According to Davies (1977:41), the system of redshift is generally referred to as the Doppler Effect, named after the 19th-century Austrian mathematician and physicist, Christian Doppler, who revealed how it works. However, in 1926, it was Edwin Hubble who substantiated that the light rays he observed were red (redshift) and therefore lengthy and, accordingly, moving away from the earth. Hubble determined that this theoretical redshift increased in proportion to the distance from our galaxy's viewpoint, and from the viewpoint of other galaxies he observed, and thus concluded that the universe is expanding. Davies (1977:150) affirms that Hubble based his theories on Doppler's observation of the colour of waves.

With reference to this, Eden (1992) corroborates Doppler's postulated principle that the observed frequency of a wave depends on the relative speed of both the source and the observer. Doppler endeavoured to use this concept as a means of explaining the colour of binary stars, which was later corroborated by Buys Ballot in 1845 (cf. Burstyn 1973; Van Everdingen 1953). The line of reasoning proposed is that sound and light are prominent throughout the cosmos. Presently, radio astronomers can effectively regulate their telescopes to pick up the radio waves being emitted by quasars, distant galaxies and the cosmic microwave background millions of light years from the earth. In this way they can compute the size of the universe. As such, it becomes evident that sound is clearly a primary vessel that can be used in unravelling the mysteries of the universe.

Taking these succinct scientific observations into consideration, as well as those that follow in this paper, it becomes pertinent to ask: when God said in Genesis 1:3 'Let there be light', what does the verse actually mean in relation to the hypothesis offered - that God used sound to create? Did God send out a specific sacred sound embedded within the initial light that fashioned everything that can be observed today? Is that sound, or indeed are those sounds and light, still reverberating throughout the universe now as observed by the Doppler Effect? Furthermore, by not relating the scientific and creationist perspectives in this way, have we missed an imperative aspect of how God brought the universe into being, including humankind, animals, plants and stars, as expressed by the Genesis account of creation? The aim of this paper is to at least commence the journey around this hypothesis, which could form the basis for more advanced work being conducted on this subject and, optimistically, bring greater lucidity on how both light and sound were used as God's mediums to construct the reality we observe today.

\section{A theology of sound}

The argument presented so far is that God used sound, carried by the initial light of Genesis 1:3, to construct the universe and that this sound is still resonating within the universe now, holding all of creation in concert. For instance, if one examines Genesis 1:1 from this perspective, one sees that there appears to be a specific emphasis on sound and expression. The following scriptural references are ascetically 
selected to demonstrate that God spoke and whilst other authors may have interpreted them differently, I choose to include them here simply to indicate this:

- Genesis 1:1 states, 'In the beginning God created the heavens and the earth.' Everything that is in the universe (or multi-universe) is included in these 10 words. Furthermore, each day of the creation week commences with, 'And God said [or articulated a sacred sound] ...'

- Psalms 33:6 says, 'By the Word of the Lord were the heavens made; and all the host of them by the breath of his mouth.'

- Hebrews 1:3f reads, 'Who being the brightness of his glory, and the express image of his person, and upholding all things by the word [or sacred sound] of his power ...'

Scripture is unambiguous in telling us that not only did God create the world and all that is in it by his Word, but that he still preserves it through his Word now. In other words, over and above the 'what', we meet, to a certain extent, the 'how' of creation too! One could advance this metaphor and propose that not only are we dealing with a universe brought into existence and sustained by sound, but that these sounds are harmonic frequencies, arranged by God to bring into being certain structures and forms, that is, the creation that we see today (Gn 1:31). To begin, one would start with Genesis 1:1-3.

Waltke and O'Connor (1990:650-651) fittingly state that there are grammatical difficulties associated with the conjunctions that connect verses 1-3 of Genesis 1, which certainly impacts one's understanding of the relationship between the three verses. However, according to the New English Translation (NET) Bible, there are two ways of looking at these difficulties. Firstly, Genesis 1:1-2 could be referring to the original act of creation with the rest of the days of the creation events completing it; hence, the disjunctive clauses of verse 2 break the sequence of the creative work of the first day. Secondly, it may possibly be seen as a précis of what the chapter will record from verses 3-31, pertaining to God creating the world as we know it. The narrative that follows in the NET Bible certainly favours the second view, seeing as that verses 1 and 2 are considered summary statements of what the rest of the chapter will record in verses 3-31.

Crucial to the proper unfolding of this argument, I consider the events of Genesis through the lens of the literary framework theory, accordingly affirming the creation week structure to be more figurative than literal. Mortenson and Ury (2008:212) properly state that the creation week is intended to present God's activities of creation, rather than a literal sequential week as we know it. It is inferred that the figurative nature of the creation account demonstrates that it is arranged topically, rather than chronologically. But, in stating this, one must consider that the events that took place were actual, yet metaphorically and figuratively presented. According to Lakoff and Johnson (1981:3-13), a metaphor is simply understanding and experiencing one kind of thing in terms of another. In the following section, the idea of how this could have occurred scientifically, using the ideas gleaned from the metaphorical and figurative account of the creative acts of Genesis is explored. The views expressed so far, and those to come, determine that sound embedded within light - being the initial creative force - consequently involves Genesis 1:3 as the initial beginning of the creative process.

Nevertheless, regardless of the view to which one ascribes, verse Genesis 1:3 is most important in developing this argument further. Epigrammatically, one could state that $\mathrm{v}$. 3 begins the narrative sequence proper. What follows, is an endeavour to expound on this using the laws of physics.

\section{Laws of physics and creation}

Based on Keil and Delitzsch's (1973) understanding of Genesis 1:1, one can assume that there was no matter when God initially spoke:

And the earth was [not became] waste and void. The alliterative nouns tohu vabohu, the etymology of which is lost, signify waste and empty [barren], but not laying waste and desolating. Whenever they are used together in other places [Is 34:11; Jr 4:23], they are taken from this passage; but tohu alone is frequently

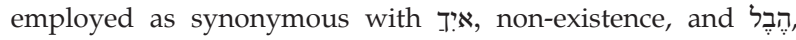
nothingness [Is 40:17; Is 40:23; Is 49:4].

(Keil \& Delitzsch 1973:46-47)

It is also implied in Hebrews 11:3 that God formed the worlds with no pre-existing matter or energy (ex nihilo). However, one can infer from this verse, and in line with the flow of this argument, that because the basic units of matter are too small to see, that is, not visible to the naked eye, it can be referring to the building blocks of matter, which, according to Pommerville (2009:42-43), are elements such as atoms, protons, neutrons, electrons, energy and the different 'waves' that one cannot observe. According to the assertions that will follow, Hebrews 11:1 could possibly be read as follows:

God used faith [substance] and the word [energy] to create the universe. He spoke [sound/vibration/light] and His Words released and caused the substance that became the stars and planets, and all we see today.

$(\mathrm{Hb} 11: 1)$

Contemplating this, Cady (2009:6-7) rightly states that God is spirit (Jn 4:24), that is, $\pi v \varepsilon \mu \alpha \theta$ cós. God has no tangible existence. He is the Creative Energy which is the cause of all visible things. God as Spirit is the invisible life and intelligence which underlies all physical things. There could be no body of visible parts to anything unless there was first spirit as creative cause.

Consequently, I presuppose that the key to unlocking this mystery of creation out of nothing (ex nihilo) is to be found within the elements of his spoken Word. God's Word is endued with energy and energy can be formed into matter (see Pommerville 2009). The frequencies, also inherent in God's spoken Word (sound with light) then shaped the matter into what we see today, as expressed by the creative verses found in Genesis 1:4-31. High-energy particle physicists are currently conducting experiments at the CERN laboratories 
in Switzerland and Fermilab in Illinois to turn energy into matter by colliding less-massive particles together with the help of accelerators. Their purpose is to find the Higgs particle (sometimes referred to as the 'god particle'). Note that this article will not concern itself specifically with the Higgs particle, but rather provide a brief explanation on its value.

According to the Encyclopaedia Britannica (2009), the Higgs particle is a hypothetical particle that is postulated to be the carrier particle, or boson of the Higgs field, a theoretical field that permeates space and endows all elementary subatomic particles with mass through its interactions with them. The Higgs particle is different from other fundamental fields, such as the electromagnetic field discussed in this paper. Thus, accordingly, and as stated, with all the technology available to scientists today, they still cannot 'see', as put forward by Hebrews 11:1, all the matter used to create. One of their main purposes is to find the illusive 'god particle' (Higgs boson) which is the theoretical final piece in a theory of everything.

The following will show that this theory of particle creation is probable, based on the current formulas for physics that are allied to energy, frequencies and light, vis-à-vis the creation acts of Genesis 1:4-31. This argument is essential to the focus of the paper, as it goes directly to the supposition that God's initial spoken Word was a form of light, embedded (or surrounded) with all the initial elements to create matter, which, in reality, it did. As proposed, everything that has matter consists of energy, is made of atoms and is entrenched with protons, neutrons and electrons. Within these elements, physicists are now also confronted with quarks and leptons. Only time and more advanced methods will show what is still there, which cannot be observed at this time. However, the author infers that the protons within the atoms are part of the substance that created the initial light spoken by God in Genesis 1:3. This is adequately explained by Van der Waerden (1968):

The electromagnetic theory of light not only gives a wonderfully adequate picture of the propagation of radiation through free space, but has also, to a wide extent, shown itself adapted for the interpretation of the phenomena connected with the interaction of radiation and matter. Thus a general description of the phenomena of emission, absorption, refraction, scattering, and dispersion of light may be obtained on the assumption that the atom contains electrified particles which can perform harmonic oscillations around positions of stable equilibrium, and will exchange energy and momentum with the radiation fields according to the classic laws of electrodynamics.

(Van der Waerden 1968:160)

It is also interesting to note the reference to harmonic oscillation in this statement, which is so imperative to this argument.

Evidently, and as stated, light can and does exemplify waves. This is further explicated by Planck's equation, which affirms that, in addition to being a quanta of energy, each photon also has a precise frequency and wavelength allied to it (see Kotz, Treichel \& Townsend 2009:273). This is made clear in Planck's equation: $E=\mathrm{h} v$, where $E$ (energy of the photon) equals $\mathrm{h}$ (Planck's constant) multiplied to $v$ (wavelength of the photon) (Trefil 2003:323). In essence, his formula shows that atoms - the building blocks of matter - vibrate at different frequencies (some high and some low) and that they emit light.

To further cement this conception, Douglas Harper (n.d.)

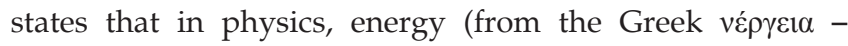
energeia, 'activity, operation', and vepyós - energos, 'active, working') is a quantity that is often understood as the ability to perform work. Thus, when God sent forth his spoken Word (as light), it was sent not only to create the needed mass via the energy embedded in the light, but to work (form) the mass into what we now see as God's creation through the harmonic frequencies entrenched in this light. This theory will be developed by showing the empirical experiments of sound frequencies on matter conducted by Hans Jenny and Ernest Chladni (see below).

It seems reasonably clear that the life-giving particles surrounding the light of his Word spoken at the beginning of time and space are still holding creation together, sustaining life and bringing forth new life continuously. It is not by chance that God's first creative act was the creation of spoken light, seeing as it surrounds and is embedded with the building blocks of matter. For Guyot (1885:35-36), Genesis 1:2 refers to matter in its primordial state and, in Genesis 1:3, God shows the author of Genesis how this primordial matter came into existence. Therefore, to encapsulate, it can be stated that in the beginning there was nothing until God spoke forth light, which carried all the elements to create matter, shape it and then bring forth life from that matter, as shown by Genesis 1:3-31. This would include the creation of Adam, and all the elements needed to sustain his life amongst this created matter. I will now illustrate how the form of matter has been shown to change depending on the frequency or soundwave used in its creation. What follows are brief biographies of two researchers who pioneered and published their findings around sound and its creative power and who set the tone for what is today know as Cymatics, the study of wave phenomena which are typically associated with the physical patterns produced through interacting sound waves in a medium.

\section{Ernest Chladni}

It is stated by Stöckmann (1999:15) that, at the end of the 18th century, an inventor and musician by the name of Ernest Chladni conceived by chance, that when the vibrations of a violin bow are applied to dust that has been randomly distributed on glass and plates, consistent patterns and figures emerged and formed. This gave rise to the idea that it was possible to make sound visible. Thus, according to Cheshire (2006:10), Chladni's major achievement was finding a way to make visible what sound waves generate. The patterns and shapes he produced today go by the term 'Chladni figures'. 
His findings were published in 1787 as Entdeckungen über die Theorie des Klangesor [Discoveries concerning the theory of music].

\section{Hans Jenny}

In addition to Chladni's research, Hans Jenny, a Swiss doctor, artist, and researcher, developed, in 1967, an instrument called the tonoscope ${ }^{2}$ with the use of crystal oscillators, which helped Jenny to further develop Chladni's initial work. In his published book, Kymatik - Wellen und Schwingungen mit ihrer Struktur und Dynamik [Cymatics - The structure and dynamics of waves and vibrations], Jenny, as with Chladni two hundred years earlier, demonstrated what materialises when one takes various materials, such as sand, spores, iron filings, water and viscous substances, and places them on vibrating metal plates and membranes. What then materialises are shapes and motion-patterns which vary from those virtually perfectly ordered and stationary, to those that develop organically and are constantly in motion, as he altered the frequencies from low to high (cf. Jenny 1974). Jenny also researched the effects of certain vowel sounds and his results confirmed that they also have the capacity to form shapes, depending on the frequency of the vowel sound itself. Jenny photographed and comprehensively documented many of these structures formed by sound and words in work mentioned above.

\section{Words and sounds generate shape}

For the purposes of this paper, the pertinent question in this regard is: how is this possible? If, as stated, we live in a universe influenced and kept in concert by sound frequencies, could one impose sound to bring about healing, order and balance to the human body? Could it be possible that through the fall of humankind, much of what we perceive of reality and its downfall is because we are harmonically 'out of synch' with God's primary purpose and design for humankind? Furthermore, has God given us the capability and the directive to correct and bring balance - within the restrictions of his Word - to afflicted persons? It is well documented that many cultures sing or chant their ancient vowels, producing musical tones to use as a form of healing. As a consequence, one can ask whether the ancient Hebrews and Indians were enlightened to this. If so, is there value to the concept of 'sacred language'? Thus, what intrinsic worth does this possess amongst the Tibetan, Egyptian and Chinese people with whom it is frequently associated? More so, do they have the potential to influence and transform physical reality to fashion occurrences through the inherent power that sound appears to possess?

It has been explained that sound as a medium can certainly change the shape of matter. Sound has the aptitude to generate and form distinctive shapes using various tones, as demonstrated by Chladni and Jenny. Consequently, the question of whether God could have used a specific tone (spoken Word), which when directed to the clay, formed and shaped Adam's body, appeals for an answer. 'And The Lord God formed man from the dust of the ground and breathed into his nostrils the breath of life, and man became a living

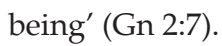

\section{Adam, our archetype}

The word Adam, derived from the Hebrew pronunciation aw-dawm meaning 'red earth', or 'red clay', indicates that Adam's body was composed of natural earth elements. Successive bodies since are equally composed of the same elements. Adam was the archetype of that of which human beings would consist. For example, Isaiah refers to all of humanity as clay in God's hands. Isaiah 64:8 states: 'Yet, O Lord, you are our Father. We are the clay, you are the potter; we are all the work of your hand'. Furthermore, scripture clearly states that because Adam came from the ground, to the ground he will return:

By the sweat of your brow you will eat your food until you return to the ground, since from it you were taken; for dust you are and to dust you will return.

(Gn 3:19)

This is also expressed of all who die. It is written in Ecclesiastes 12:7: 'Then shall the dust (out of which God made man's body) return to the earth as it was, and the spirit shall return to God Who gave it'.

\section{Divine action, miracles and sound}

According to Barrett (2004:142), there is no reservation that divine action is a long-standing subject of debate. If the world is no longer construed by the mechanistic Newtonian picture, but rather as a world of flexibility and openness to change, what is the manner and scope of divine action and wherein lies the causal joint? In Lewis's (2002:77) analysis, 'It seems reasonable to suppose that the Creator was specifically interested in man and might even interrupt the course of nature for his benefit.' Yet the question remains: where does God actually act, and how does he act? Can nature be known to be of such a kind that supernatural interferences are possible? Furthermore, if one grants the existence of a power outside nature, is there, according to Lewis (2002:88), 'any intrinsic absurdity in the idea of its intervening to produce within nature, events which the regular "goings-on" of the whole natural system would never have produced'?

From a theological perspective, one may perhaps say that when miracles do transpire, natural laws are countered by supernatural forces (see Lewis 2002:59-61). In this view, the laws of nature are not suspended but continue to perform. In the process, a supernatural law is introduced negating the affect of the natural law. Perhaps God's activity, or 'energy', to use a modern expression, is always and everywhere available, like an extended field or supporting context. Perhaps, in time, science would come to accept that the Higgs field being postulated by particle scientists (as previously referred to) is indeed God's creative force. Pannenberg (1994:83), for example, argues that the Spirit of God may be viewed (metaphorically) as a dynamic field. According 
to Pannenberg (1994:13), the unified field theory in physics, as proposed by Einstein (1950:13-17), is theologically significant. It provides a possible means for conceiving of the divine Spirit as active in the natural world. Hypothetically, Pannenberg (1994:14) believes that the spirit is not like a force field, but the spirit is a force field, and here he makes an ontological claim. If, hypothetically, the spirit is (like) a force field, it would give more credence to the view that God employed sound, a dynamic force field, to bring creation into existence.

For Lewis (2002:92), the natural sciences are of the opinion that a miracle is a form of doctoring or tampering with the inflexible laws of nature. This means an additional cause is introduced, that is to say, a supernatural force, which the scientist has not considered. Conversely, if the laws of nature are necessary truths, then no miracle can contravene them. But according to Lewis (2002:93), no miracle needs to contravene them because a miracle is with nature. Rather, what it contravenes, he further states, is our understanding of nature.

Nichols (2002:712) offers that it may be that God acts at the quantum level, as proposed by Barbour (2000:170), as the determiner of indeterminacies. Quantum states, which are indeterminate, are determined by divine activity to influence physical processes. This is where the aspect of sound (spoken harmonic tones) is most appreciated. An effortless variation of tone could, in effect, produce a modification in structure or form, giving the appearance of an extraordinary phenomenon depicted as a miracle. God could be viewed as the great conductor orchestrating sound, to bring forth change in natural forms and structures as he wills, which are then perceived as miracles.

According to Elson (2004:114), an illustration of this is the biblical account of Israel's priests utilising the vibrations produced by blowing upon a ram's horn or shofar to bring down the walls of Jericho (Jos 6:20). Although this may be criticised as naive realism, archaeological research has not yet reached consensus on the event and is still determining the exact cause of this occurrence. Conversely, one can presuppose now that this is yet another allusion to the power of sound. As has been shown, all matter contains the same building blocks; all of which are embedded within the primary one, the vibrating atom (see Breithaupt 2000:206).

If this is the case and sound is one of the mediums holding the universe together - and based on how slightly changing the tone of a frequency can initiate objects to transmute into one form or another - it would explain how God could alter natural laws by simply adjusting the current tone holding the particular object or shape in place. This then stimulates, at the quantum level, the existing object or structure 'miraculously' to modify or disintegrate, as with the walls of Jericho. This was shown to be a demonstrable actuality by Hans Jenny and Ernest Chladni in their profuse research. Sound, directed at matter, clearly has the aptitude to generate and form distinctive shapes using various harmonically manipulated tones. As a result, if events come from beyond this realm, they will cause no inconvenience or discomfort to the natural realm. The moment the 'miraculous' enters the natural realm it abides by all the laws of nature, that is, the law of frequencies or sacred sound construed as holding created matter together.

However, one does need to walk circumspectly whilst making statements implying that the ultimate cause of occurrences is directly linked to sound. This implies that sound has inherent power that scripture ascribes to God alone. It would be irrational to repudiate that God is the ultimate cause of all occurrences. The ultimate cause, God, determines the outcome of everything. Sound is therefore only a secondary cause, not the ultimate cause. Without this ultimate cause, the desired occurrence will not materialise. This proclamation immediately should separate the hypothesis of this paper from New Age and similar pseudo-sciences, which uphold sound as the ultimate cause of everything. God is not bound to act in any event directly as the ultimate cause, but uses, as he pleases, secondary causation, in this instance, sound.

\section{Conclusion}

As revealed throughout this paper, light and sound have expressions of power from the super-macro of the universe, right down to the uttermost reaches of subatomic space, as shown in the super string theory. This means the subatomic particles we observe in nature are nothing more than dissimilar resonances of the vibrating superstrings, in the equivalent manner that different musical notes emanate from the diverse modes of vibration of a violin string.

The overarching question of this paper was: did God project out a specific empowered sacred sound or sounds at the commencement of creation, which fashioned creation through the elements surrounded by light and which subsequently created everything else we witness today, including constructing the first man, Adam? In answer to this, the argument presented herein gives the impression that all naturally occurring structures and shapes - from the subatomic electron to the individual atomic elements, and from microscopic forms to planets, stars and galaxies, were ultimately created from intelligently designed and organised bundles of waveforms, possessing precise elements, geometric structure and symmetry, formed and sustained by harmonic vibrating atoms, God's secondary cause. It was then expressed that if the universe is kept in concert by sound frequencies, there is a possibility that one could one impose sound to bring about healing, order and balance to the human body. It was further shown that there is a scriptural basis for this, which was strengthened by briefly referencing research carried out in this field and confirming results of this research.

\section{Acknowledgements}

I would like to acknowledge the School of Theology at the University of Pretoria for funding this article. My special thanks also go to Prof. Johan Buitendag, the Dean of the School, for his help. 


\section{Competing interests}

The author declares that he has no financial or personal relationship(s) which may have inappropriately influenced him in writing this paper.

\section{References}

Barbour, I.G., 2000, When science meets religion, Society for Promoting Christian Knowledge, London.

Barrett, P., 2004, Science and theology since Copernicus, T\&T Clark International, London.

Breithaupt, J., 2000, New understanding physics for advanced Level, Nelson Thornes, Cheltenham.

Burstyn, H.L., 1973, 'Buys Ballot, Christoph Hendrik Diederik', Dictionary of Scientific Biography vol. 1, p. 628, Scribners, New York, NY

Cady, E., 2009, Lessons in truth, Biblio Bazaar, Charleston, SC.

Cheshire, G., 2006, Sound and vibrations: Science essentials physics, Evans Brothers, London.

Chladni, E.F.F 1787, Entdeckungen über die Theorie des Klanges [Discoveries in the theory of sound], Bey Weidmanns Erben und Reich, Leipzig.

Davies, P.C.W., 1977, Space and time in the modern universe, Cambridge University Press, Cambridge.

Donlan, J.E., 2008, Ordaining reality: The science behind the power of positive thinking, Universal Publishers, Boca Raton, FL.

Eden, A., 1992, The search for Christian Doppler, Springer-Verlag, Vienna.

Einstein, A., 1950, 'On the generalized theory of gravitation', Scientific American CLXXXII (4), 13-17. http://dx.doi.org/10.1038/scientificamerican0450-13

Elson, S.S., 2004, Kabbalah of prayer: Sacred sounds and the soul's journey, Steiner Books, New York, NY.

Encyclopaedia Britannica, 2009, CD-ROM, 'Higgs particle', in Encyclopaedia Britannic 2009 Ultimate Reference Suite, viewed 15 September 2010, Encyclopaedia Britannica, Chicago, IL.
Guyot, A., 1885, Creation, Scribner, New York, NY.

Harper, D., n.d, 'Energy,' in Online Etymology Dictionary, viewed 01 October 2010 from http://www.etymonline.com/index.php?term=energy

Jenny, H., 1967, Kymatik - Wellen und Schwingungen mit ihrer Struktur und Dynamik [Cymatics - The structure and dynamics of waves and vibrations], Basilius Press, Basel.

Jenny, H., 1974, Cymatics, vol. 2, Basilius Press, Basel.

Keil, K. \& Delitzsch, F., 1973, Pentateauch, 3 vols, Biblical commentary on the Old Testament, Eerdmans, Grand Rapids, MI.

Kotz, J.C., Treichel, P. \& Townsend, J.R., 2009, Chemistry and chemical reactivity, vol 2, Cengage Learning, London.

Lakoff, G. \& Johnson, M., 1981, Metaphors we live by, University of Chicago Press, Chicago, IL.

Lewis, C.S., 2002, Miracles, Harper Collins, New York, NY.

Mortenson, T. \& Ury, T.H., 2008, Coming to grips with Genesis: Biblical authority and the age of the Earth, New Leaf Publishing, Orlando, FL.

Nichols, T.L., 2002, 'Miracles in science and theology', Zygon 37(3), 703-715. http:// dx.doi.org/10.1111/1467-9744.00447

Pannenberg, W., 1994, Systematic theology, vol. 2, Eerdmans, Grand Rapids, MI.

Pommerville, J.C., 2009, Alcamo's fundamentals of microbiology: Body systems, Jones \& Bartlett Learning, Sudbury, MA.

Porter, J., 2008, The Psions' guide, Lulu Inc., Raleigh, NC.

Pretorius, M., 2008, 'Cymatic theology', Theological-Research Org, August, 1-4.

Sklar, L., 1977, 'Space, time, and space-time', The philosophy of science, vol. 164 of campus, University of California Press, Berkeley, CA.

Stöckmann, H.J., 1999, Quantum chaos: An introduction, vol. 3, Cambridge nonlinear science series, Cambridge University Press, Cambridge.

Trefil, J.S., 2003, Thenature of science: An A-Z guide to the laws and principles governing our universe, Houghton Mifflin Harcourt, Boston, MA.

Van der Waerden, B.L. (ed.), 1968, Sources of quantum mechanics, Courier Dover Publications, New York, NY.

Van Everdingen, E., 1953, C.H.D. Buys Ballot 1817-1890D, A Daamen, The Hague.

Waltke, B. \& O'Connor, M., 1990, An introduction to biblical Hebrew and syntax Eisenbrauns, Winona Lake, IN. 